American Journal of Pharmaceutical Education 2020; 84 (9) Article 7970.

\title{
BRIEF
}

\section{An Exploratory Assessment of Epistemic Curiosity in Students at Three Doctor of Pharmacy Programs}

\author{
Daniel R. Malcom, PharmD, ${ }^{\text {a,b }}$ Jeff Cain, EdD, MS, ${ }^{\mathrm{c}}$ Emily K. Frederick, PharmD, ${ }^{\mathrm{a}}$ \\ Chris Johnson, PharmD, MEd ${ }^{\mathrm{d}}$ \\ ${ }^{a}$ Sullivan University, College of Pharmacy and Health Sciences, Louisville, Kentucky \\ ${ }^{\mathrm{b}}$ Associate Editor, American Journal of Pharmaceutical Education, Arlington, Virginia \\ ${ }^{\mathrm{c}}$ University of Kentucky, College of Pharmacy, Lexington, Kentucky \\ ${ }^{\mathrm{d}}$ University of Arkansas for Medical Sciences College of Pharmacy, Little Rock, Arkansas \\ Submitted December 19, 2019; accepted May 31, 2020; published September 2020.
}

Objective. To determine the level of epistemic curiosity in a sample of student pharmacists from three Doctor of Pharmacy (PharmD) programs as well as any differences in epistemic curiosity levels that exist between programs and with regard to professional year.

Methods. Litman's Epistemic Curiosity Scale (ECS) was administered to student pharmacists at three different PharmD programs. Descriptive statistics were calculated, and overall mean ECS scores as well as mean scores on epistemic curiosity motivated by intellectual interest (I-type) and informational deprivation (D-type) were compared among student pharmacists at the three institutions using analysis of variance. Reliability analyses were also performed on the data.

Results. A total of 569 out of 1143 eligible students responded to the survey, for an overall response rate of 49.8\%. The mean overall ECS score was $27.6(\mathrm{SD}=4.9)$. Mean I-type epistemic curiosity was $14.9(\mathrm{SD}=2.8)$ overall, but was statistically different among the schools. Mean D-type epistemic curiosity was $12.7(\mathrm{SD}=3.2)$ overall, but was statistically similar among the programs. Overall, the data demonstrated good internal consistency, with a Cronbach's alpha of .81 .

Conclusion. This study was the first to characterize epistemic curiosity in student pharmacists and included data from multiple years and multiple programs. Future analyses should investigate associations between epistemic curiosity and other factors of interest to help elucidate how better understanding epistemic curiosity or enhancing it in student pharmacists may help facilitate student success.

Keywords: curiosity, epistemic curiosity, students

\section{INTRODUCTION}

The amount of information available in the world is expanding at a rapid pace, with one recent estimate putting the amount of data generated per day at 2.5 quintillion bytes. ${ }^{1}$ Simultaneously, the evolving role of the pharmacist has left schools challenged with what to include in curricula. ${ }^{2}$ Pharmacy programs can no longer directly teach all information necessary for practice; however, an enhanced focus on abilities and skills, coupled with an understanding of underlying motivation and information processing, can foster an important foundation for personal and professional success. An increased focus on self-motivated lifelong learning is critical.

Corresponding Author: Daniel R. Malcom, Sullivan University, College of Pharmacy and Health Sciences, 2100 Gardiner Ln., Louisville, KY 40205. Tel: 502-413-8969.

Email: dmalcom@sullivan.edu
At the core of understanding why and how we learn lies curiosity, a concept discussed by psychologists and educators for centuries. ${ }^{3}$ The psychological construct underlying curiosity is most commonly referred to as epistemic curiosity. Epistemic curiosity is characterized as an innate desire to gain knowledge that motivates someone to learn new ideas, minimize gaps in information, and solve complex problems requiring critical thinking. ${ }^{4}$ Research into epistemic curiosity has characterized two separate yet correlated dimensions of motivation: intellectual interest (I-type) and information deprivation (D-type). ${ }^{5}$ Individuals may possess either or both types of motivation, and the two types are not known to conflict or compete with one another. Individuals with I-type epistemic curiosity employ critical thinking as an enjoyable experience, anticipating the pleasure of new discoveries. Individuals with D-type epistemic curiosity seek out new information in a desire to eliminate the 


\section{American Journal of Pharmaceutical Education 2020; 84 (9) Article 7970.}

unpleasant feelings of uncertainty or ignorance. ${ }^{6}$ Neuroscience research has begun to elucidate the circuitry linking epistemic curiosity to memory and activation of the reward pathway in the brain, and, on a broader scale associating it with effective learning. ${ }^{7-9}$ Psychological investigation has begun to associate intellectual curiosity with academic performance, thus making it a relevant concept to consider in the classroom and workplace. ${ }^{10,11}$

As curiosity is linked to learning, there is interest in determining whether curiosity can predict success in higher education, including in pharmacy education. Recent medical and pharmacy literature discuss the potential role of epistemic curiosity in learning and as a parameter of interest when assessing applicants and students. ${ }^{12-14}$ Curiosity is noted in the in the 2011-12 Argus Commission Report and the 2013 Center for the Advancement of Pharmacy Education (CAPE) Outcomes as a "habit of mind" of characteristically successful people and part of the appropriate knowledge, skills, and attitudes that pharmacy program graduates should have. ${ }^{15,16}$ In previous studies of general undergraduate students, I-type motivation has been associated with increased interest and engagement with the material, which supported development of "mastery-oriented" learning goals. ${ }^{4,5}$ In job settings, desire to learn new skills has been associated with I-type motivation, while an underlying desire to learn about and solve specific problems has been associated with D-type motivation. ${ }^{6}$

Despite these findings, little is known about epistemic curiosity among graduate and health professions students such as those in pharmacy. Furthermore, there is no evidence in such programs to-date for what, if any, implications epistemic curiosity could have or to what degree it may help inform admissions, progression, or placement. Given this growing body of evidence citing the importance and varied connections with curiosity, this initial pilot study in pharmacy sought to assess and characterize the level of epistemic curiosity in student pharmacists at three programs. Second, this research sought to identify any differences in epistemic curiosity among programs and a student's year of study in the respective program.

\section{METHODS}

A 12-question self-report survey instrument was delivered anonymously via Microsoft Forms (Microsoft Corporation, Redmond, WA) from August to September 2019. Litman's Epistemic Curiosity Scale (ECS) was used in addition to two demographic questions regarding which institution the respondent attended and the year of the respondent in the program. ${ }^{5}$ Litman's scale was chosen over other tools as it was free to use for research purposes, designed specifically to assess epistemic curiosity (vs other aspects or components of curiosity), and has been used extensively in college students in the literature. Additional demographic questions were not included in this pilot study in an effort to decrease survey burden. The ECS contains 10 Likert-type items rated on a scale of one to four, with scores ranging from 10 to 40 . All items are positively worded and scored identically. Five items on the scale represent I-type epistemic curiosity and five represent D-type epistemic curiosity, with scores on each subscale ranging from 5 to 20 . The are no current validated score classifications (eg, high, normal, low). Data are reported as mean with standard deviation of the overall scale score, as well as the mean I-type and D-type epistemic curiosity scores.

Participants in this cross-sectional study were student pharmacists in all program years at three doctor of pharmacy (PharmD) programs in the United States: Sullivan University College of Pharmacy and Health Sciences (SU COPHS) in Louisville, Kentucky, University of Kentucky College of Pharmacy (UKCOP) in Lexington, Kentucky, and the University of Arkansas for Medical Sciences College of Pharmacy (UAMS COP) in Little Rock, Arkansas. Sullivan University COPHS is a private three-year accelerated PharmD program, while both UAMS COP and UKCOP are public four-year PharmD programs. The study was deemed exempt by the institutional review boards at all three schools.

Results were downloaded from Microsoft Forms into a spreadsheet for further analysis. Statistics were performed using Excel 2016 and SPSS Statistics, version 23 (IBM, Aramonk, NY). Mean overall ECS scores as well as I-type and D-type motivation scores were compared between programs using analysis of variance (ANOVA). Additionally, overall mean ECS scores were compared by year in program using ANOVA. A significance level of .05 was established a priori for all statistical tests. Multiple reliability analyses were conducted on the data, including Cronbach's alpha, corrected item-total correlation, and Cronbach's alpha if item deleted. ${ }^{17,18}$ Cronbach's alpha is an important component in measuring the internal consistency or interrelatedness of the various items within an instrument, and values of 7 or greater are considered desirable. ${ }^{19,20}$ Corrected item-total correlation evaluates the relationship between each item and the score on the instrument without that item. As a component in assessing the overall internal consistency of the assessment, minimum acceptable values of corrected itemtotal correlation are typically .3 or greater. ${ }^{21}$ Cronbach's alpha if item deleted is a measurement that assesses the alpha value of the overall assessment if the item being evaluated was removed. ${ }^{19}$ It is desirable for the value not 
American Journal of Pharmaceutical Education 2020; 84 (9) Article 7970.

Table 1. Program Year of Doctor of Pharmacy Students Who Participated in a Study to Determine Epistemic Curiosity $(\mathrm{N}=569)$

\begin{tabular}{lcccc}
\hline Year in Program & $\begin{array}{c}\text { All Students } \\
\text { No. (\%) }\end{array}$ & $\begin{array}{c}\text { SU COPHS (n=128), } \\
\text { No. (\%) }\end{array}$ & $\begin{array}{c}\text { UKCOP (n=254), } \\
\text { No. (\%) }\end{array}$ & $\begin{array}{c}\text { UAMS COP (n=187), } \\
\text { No. }(\mathbf{\%})\end{array}$ \\
\hline First Year (P1) & $144(25.3)$ & $43(33.6)$ & $66(33)$ & $35(18.7)$ \\
Second Year (P2) & $148(26)$ & $44(34.4)$ & $61(24)$ & $43(23)$ \\
Third Year (P3) & $180(31.6)$ & $41(32)$ & $83(32.7)$ & $56(30)$ \\
Fourth Year (P4) & $97(17)$ & N/A & $44(17.3)$ & $53(28.3)$ \\
\hline
\end{tabular}

Abbreviations: SU COPHS=Sullivan University College of Pharmacy and Health Sciences, UKCOP=University of Kentucky College of Pharmacy, UAMS COP=University of Arkansas for Medical Sciences College of Pharmacy.

SU COPHS is a three-year program. UKCOP and UAMS COP are four-year programs

to be higher than the overall Cronbach's alpha for the instrument. ${ }^{20}$ If the alpha value of the overall assessment was higher without the item in question, it would mark that item as a candidate for removal from the assessment as its presence would decrease the internal consistency of the assessment.

\section{RESULTS}

A total of 569 of 1143 eligible students responded to the survey and consented to have their data included in the study for analysis, resulting in an overall response rate of $49.8 \%$. One hundred twenty-eight of the participants were from SU COPHS (62.4\% response rate), 254 were from UKCOP (46.6\% response rate), and 187 were from UAMS COP (47.6\% response rate). Full demographic results are shown in Table 1.

The overall mean ECS score for students at all three schools was $27.6(\mathrm{SD}=4.9)$, with an I-type epistemic curiosity mean of $14.9(\mathrm{SD}=2.8)$ and a $\mathrm{D}$-type epistemic curiosity mean of $12.7(\mathrm{SD}=3.2)$, shown in Table 2 . The ANOVA results showed a significant difference among the overall mean ECS scores $(p<.05)$ as well as the I-type epistemic curiosity scores $(p<.05)$, but there were no statistical differences between programs regarding Dtype epistemic curiosity scores $(p>.05)$.

Results comparing total mean ECS scores by year in the program are available in Table 2. First and fourth-year students in our analysis had identical mean total ECS scores $($ mean $=28.0, \mathrm{SD}=5.1)$, though this should be interpreted cautiously as the fourth-year students' scores excluded SU COPHS students because that program has no fourth year. The ANOVA results showed no significant difference in scores among students based on respective year in the program $(p>.05)$. Because of the differences in the programs' design (four-year vs three-year), a post-hoc subgroup analysis was conducted via linear regression to determine whether a student's place in the final year of the respective PharmD program (ie, third year for the threeyear program and fourth year for the four-year program) was predictive of the overall mean ECS score. One hundred thirty-eight of the 569 respondents $(24.3 \%)$ were in the final year of their PharmD program (P3 for SU

Table 2. Epistemic Curiosity Scale (ECS) ${ }^{\mathrm{a}}$ Results of Doctor of Pharmacy Students Who Participated in a Study to Determine Epistemic Curiosity Levels by Institution and Year in Program $(\mathrm{N}=569)$

\begin{tabular}{lcccc}
\hline & $\begin{array}{c}\text { All Students } \\
\text { M (SD) }\end{array}$ & $\begin{array}{c}\text { UKCOP } \\
\text { M (SD) }\end{array}$ & $\begin{array}{c}\text { UAMS COP } \\
\text { M (SD) }\end{array}$ & $\begin{array}{c}\text { SU COPHS } \\
\text { M (SD) }\end{array}$ \\
\hline Total ECS Score $^{\text {Interest (I) type }}$ & $27.6(4.9)$ & $27.4(5.2)$ & $27.2(4.6)$ & $28.7(4.7)^{\mathrm{b}}$ \\
$\quad$ Deprivation (D) type $^{\mathrm{b}}$ & $14.9(2.8)$ & $14.8(2.9)$ & $14.8(2.7)$ & $15.5(2.7)^{\mathrm{b}}$ \\
Year in Program $^{\mathrm{c}}$ & $12.7(3.2)$ & $12.6(3.3)$ & $12.4(3.1)$ & $13.2(3.1)$ \\
First Year (P1) $_{\text {Second Year (P2) }}$ & & & \\
Third Year (P3) $^{\mathrm{d}}$ & $28.0(5.1)$ & $27.7(5.3)$ & $25.9(4.1)$ & $30.2(4.7)$ \\
Fourth Year (P4) $^{\mathrm{d}}$ & $27.2(4.9)$ & $26.8(5.4)$ & $26.9(4.4)$ & $28.0(4.6)$ \\
\hline
\end{tabular}

Abbreviations: UKCOP $=$ University of Kentucky College of Pharmacy, UAMS COP=University of Arkansas for Medical Sciences College of Pharmacy, SU COPHS = Sullivan University College of Pharmacy and Health Sciences

${ }^{a}$ The ECS contains 10 Likert-type items evaluated by respondents on a scale of 1-4, 1=Almost Never, 2=Sometimes, $3=$ Often, $4=$ Almost Always. Minimum score is 10, maximum score is 40. Interest-type and Deprivation type each have a minimum of 5 and maximum of 20

${ }^{\mathrm{b}}$ Analysis of variance (ANOVA); $\mathrm{p}<.05$

${ }^{\mathrm{c}}$ ANOVA; $\mathrm{p}>.05$

${ }^{\mathrm{d}}$ SU COPHS is a three-year program. UKCOP and UAMS COP are four-year programs 
COPHS and P4 for UKCOP and UAMS COP). The mean overall ECS score for students not in the final year of the PharmD program was $27.5(\mathrm{SD}=4.9)$, while the mean score for students in the final year was $27.9(\mathrm{SD}=4.9)$. Linear regression revealed that there was no significant relationship between a student's status in the final year of the program and their mean ECS score $(\mathrm{R}=.04$, $p=.39$ ).

Reliability analyses for our results are found in Table 3. The overall Cronbach's alpha value of .81 is above the desired value of .7 and similar to values reported previously for the ECS. ${ }^{5,20}$ Cronbach's alpha values were similar between the I-type and D-type epistemic curiosity scales (.77 and .8, respectively), both of which were above the max desired value of .7. All of the items on the ECS showed a corrected item-total correlation above the desired value of .3, indicating good quality to the items as discussed previously. ${ }^{21}$ Additionally, Cronbach's alpha if item deleted values ranged from .78-.80, all lower than the overall Cronbach's alpha for the instrument of .81. This indicated that no items were candidates for removal from the instrument based on internal consistency metrics.

\section{DISCUSSION}

There are few assessments of epistemic curiosity in students in the literature to date and even fewer assessments of epistemic curiosity in health professions students, with none found for pharmacy students. Litman's initial 2008 study establishing normative scores for the ECS instrument included three separate analyses of American undergraduate students, providing data from 2145 subjects. ${ }^{5}$ The overall mean ECS scores in that study ranged from 27.3 to 32.4 across the three analyses, which were similar to our overall mean score of 27.6. Mean I-type scores ranged from 14.6 to 17.2, which was similar to our mean score of 14.9. The mean D-type epistemic curiosity score ranged from 12.7 to 15.2 , which was also similar to our mean score of $12.7 .^{5}$ Additional studies also found similar epistemic curiosity score ranges. $^{22}$

Richards and colleagues investigated epistemic curiosity in 90 third-year medical students using Litman's ECS. $^{23}$ The I-type curiosity in their student population was found to be numerically higher than the D-type, with the mean score for I-type epistemic curiosity being 16.3 $(\mathrm{SD}=2.6)$ compared to a mean D-type epistemic curiosity

Table 3. Item-Level Reliability and Internal Consistency Results for the Epistemic Curiosity Scale (ECS) ${ }^{\text {a }}$ from All Doctor of Pharmacy Students Who Participated in a Study to Determine Epistemic Curiosity Levels $(\mathrm{N}=569)$

\begin{tabular}{|c|c|c|c|c|}
\hline & $\begin{array}{c}\text { M } \\
(\text { SD) }\end{array}$ & $\begin{array}{l}\text { Corrected item- } \\
\text { total correlation }\end{array}$ & $\begin{array}{l}\text { Cronbach's alpha } \\
\text { if item deleted }\end{array}$ & $\begin{array}{l}\text { Cronbach's } \\
\text { alpha }\end{array}$ \\
\hline Interest-type (I-type) & & & & .77 \\
\hline I enjoy exploring new ideas. & $3.1(.8)$ & 46 & .79 & \\
\hline $\begin{array}{l}\text { I enjoy learning about subjects that are } \\
\text { unfamiliar to me. }\end{array}$ & $2.9(.7)$ & .46 & .79 & \\
\hline I find it fascinating to learn new information. & $3.3(.7)$ & .48 & .79 & \\
\hline $\begin{array}{l}\text { When I learn something new, I would like to } \\
\text { find out more about it. }\end{array}$ & $3(.7)$ & .49 & .79 & \\
\hline I enjoy discussing abstract concepts. & $2.6(1)$ & .41 & .80 & \\
\hline Deprivation-type (D-type) & & & & .80 \\
\hline $\begin{array}{l}\text { Difficult conceptual problems can keep me } \\
\text { awake all night thinking about solutions. }\end{array}$ & $2.3(.8)$ & 46 & .79 & \\
\hline $\begin{array}{l}\text { I can spend hours on a single problem } \\
\text { because I just can't rest without knowing } \\
\text { the answer. }\end{array}$ & $2.4(.9)$ & .53 & .78 & \\
\hline $\begin{array}{l}\text { I feel frustrated if I can't figure out the } \\
\text { solution to a problem, so I work even } \\
\text { harder to solve it. }\end{array}$ & $3(.8)$ & 47 & 79 & \\
\hline $\begin{array}{l}\text { I brood for a long time in an attempt to solve } \\
\text { some fundamental problem. }\end{array}$ & $2.4(.9)$ & .56 & .78 & \\
\hline $\begin{array}{l}\text { I work like a fiend at problems that I feel } \\
\text { must be solved. }\end{array}$ & $2.6(.9)$ & .51 & .79 & \\
\hline Overall Cronbach's alpha & & & & .81 \\
\hline
\end{tabular}

${ }^{a}$ The ECS contains 10 Likert-type items evaluated by respondents on a scale of 1-4, $1=$ Almost Never, $2=$ Sometimes, $3=$ Often, $4=$ Almost Always. Minimum score is 10 , maximum score is 40 . Interest-type and Deprivation-type each have a minimum of 5 and maximum of 20 


\section{American Journal of Pharmaceutical Education 2020; 84 (9) Article 7970.}

score of $13.3(\mathrm{SD}=3.5)$. The overall ECS mean score for the group was not reported, nor was analysis comparing groups or I-type to D-type. While the mean I-type and Dtype curiosity scores were higher than those found in our study, the difference is not appreciable, and a lack of meaningful data related to applicability and relevance of ECS scores to tangible outcomes makes comparisons challenging. Additional research is warranted.

Sternszus and colleagues explored curiosity in 402 medical students across a four-year curriculum. ${ }^{24}$ In contrast with Litman's ECS, Sternszus employed the Melbourne Curiosity Inventory (MCI). ${ }^{25}$ The MCI is designed to assess "state" curiosity (interest in a given scenario or situation) as well as "trait" curiosity (differences in individual capacity to experience curiosity). Overall, the medical students scored a mean of 64.5 $(\mathrm{SD}=8.5)$ out of 80 on the trait subscale and a mean of $58.5(\mathrm{SD}=11.6)$ out of 80 on the state subscale, which was significant $(p<.001) .^{24}$ This higher mean for trait curiosity was found across all years of the medical program, though state curiosity scores demonstrated greater variability between years. It is difficult to generalize the findings from this study and compare the results to those from our assessment, which used a different scale and assessed a different aspect of curiosity (time- or situationrelated curiosity). However, like ours, this study was exploratory in nature and the levels of curiosity were consistent across years of the program. The authors discussed the potential uses of these results in designing curricula to foster higher levels of curiosity, as it was identified as an important trait for medical practice. ${ }^{24}$

Previous authors have elaborated on the importance of studying student pharmacist curiosity with regard to classroom learning and career optimization. ${ }^{13,14}$ The first research step is to understand current levels of curiosity in the pharmacy student population. The results of this study provide an initial baseline assessment of epistemic curiosity in student pharmacists. Further assessment of epistemic curiosity and any interventions aimed at improving epistemic curiosity in student pharmacists may help programs in developing their students within Domain 4 of the CAPE outcomes. ${ }^{15}$ Additionally, higher levels of epistemic curiosity may aid in students' ability to adapt to and lead change in an ever-changing pharmacy and health care environment.

While the sample size of this cross-sectional study was large relative to that in other studies of epistemic curiosity, our response rate was approximately 50\%. Thus, nonresponse bias is possible, and it is unclear what effect this may have had. However, our study did include three pharmacy programs of diverse types with diverse characteristics, including two four-year traditional public institutions and a three-year private institution.
Additionally, our response rate is in line with other studies of epistemic curiosity conducted in health professions students, including a study by Sternszus and colleagues that had a $53.5 \%$ response rate and only 402 students. $^{24}$ While no response rate was reported for Richards and colleagues, that study only included 90 medical students, whereas our study included over 550 students. ${ }^{23}$ Larger studies with more diverse populations of health professional students should be conducted.

While research into epistemic curiosity as a construct is relatively new, the word curiosity has a positive connotation, and therefore, social desirability bias may lead to overreporting or inflation of scores. ${ }^{26}$ Due to the pilot nature of this research, the sex and age of respondents was not collected. Thus, we were unable to assess the effect of those demographic variables on epistemic curiosity levels. Future research will include more demographic variables as well as other factors possibly predictive of epistemic curiosity. Finally, this survey was based on students' selfreported data, and may include inaccuracies due to recall bias. While cross-sectional by design to capture a large number of respondents at the same time, this study was not longitudinal in nature; thus, changes in the students' epistemic curiosity over time could not be determined from the data gathered. Additionally, due to the study design and other limitations noted, we are unable to comment on any causal relationships present in the data.

\section{CONCLUSION}

This pilot study was the first to characterize epistemic curiosity in student pharmacists and included data from three institutions that differed in program characteristics and size. Future research into epistemic curiosity should identify factors predictive of epistemic curiosity and its impact on learning outcomes and curricular initiatives that may increase epistemic curiosity in student pharmacists.

\section{REFERENCES}

1. Marr B. How Much Data Do We Create Every Day? The MindBlowing Stats Everyone Should Read. Forbes. May 21, 2018. Accessed August 28, 2020.

2. Romanelli F. Curricular hoarding. Am J Pharm Educ. 2020;81(1):Article 847714.

3. Dewey J. How We Think. London: Heath \& Co. 1910.

4. Litman JA, Jimerson TL. The measurement of curiosity as a feeling of deprivation. J Pers Assess. 2004;82(2):147-157.

5. Litman JA. Interest and deprivation factors of epistemic curiosity. Pers Individ Differ. 2008;44(7):1585-1595.

6. Litman J. Curiosity: Nature, dimensionality, and determinants. The Cambridge Handbook on Motivation and Learning.

2019:418-422.

7. Kang MT, Hsu M, Krajbich IM, et al. The wick in the candle of learning: epistemic curiosity activates reward circuitry and enhances memory. Psychol Sci. 2009;20(8):963-973. 


\section{American Journal of Pharmaceutical Education 2020; 84 (9) Article 7970.}

8. Gruber MJ, Gelman BD, Ranganath C. States of curiosity modulate hippocampus-dependent learning via the dopaminergic circuit. Neuron. 2014;84:1-11.

9. von Stumm S, Hell B, Chamorro-Premuzic T. The hungry mind: intellectual curiosity is the third pillar of academic performance. Perspect Psychol Sci. 2011;6(6):574-588.

10. Reio TG, Wiswell A. Field investigation of the relationship among adult curiosity, workplace learning, and job performance. Hum Resour Dev Q. 2000;11(1):1-30.

11. Dyche L, Epstein RM. Curiosity and medical education. Med Educ. 2011;45(7):663-668.

12. Ellaway RH. When I say ... epistemic curiosity. Med Educ. 2014;48(2):113-114.

13. Cain J. We should pay more attention to student curiosity. Curr Pharm Teach Learn. 2019;11(7):651-654.

14. Malcom DR. Curiosity and knowledge are vital components of curricular reform. Am J Pharm Educ. 2019;83(1):Article 7503.

15. Medina MS, Plaza CM, Stowe CD. Center for the Advancement of Pharmacy Education 2013 Educational Outcomes. Am J Pharm Educ. 2013;77(8):Article 162.

16. Speedie MK, Baldwin JN, Carter RA, et al. Cultivating 'habits of mind' in the scholarly pharmacy clinician: report of the 2011-12 argus commission. Am J Pharm Educ. 2012;76(6):Article S3.
17. Peeters MJ, Beltyukova SA, Martin BA. Educational testing and validity of conclusions in the scholarship of teaching and learning. Am J Pharm Educ. 2013;77(9):Article 186.

18. Cor MK. Measuring social science concepts in pharmacy education research: from definition to item analysis of self-report instruments. Curr Pharm Teach Learn. 2018;10(1):112-118.

19. Robert DF. Scale Development: Theory and Applications. 2nd ed. Thousand Oaks, CA: Sage Publication; 2003.

20. Tavakol M, Dennick R. Making sense of Cronbach's alpha. Int J Med Educ. 2011;2:53.

21. Field A. Discovering Statistics using SPSS. Upper Saddle River, NJ: London: SAGE Publications Ltd; 2009.

22. Lauriola M, Litman JA, Mussel P, et al. Epistemic curiosity and self-regulation. Pers Individ Differ 2015;83:202-207.

23. Richards JB, Litman JA, Roberts DH. Performance

characteristics of measurement instruments of epistemic curiosity in third-year medical students. Med Sci Educ. 2013;23(3):355-363.

24. Sternszus R, Saroyan A, Steinert Y. Describing medical student curiosity across a four-year curriculum: an exploratory study. Med Teach. 2017;39(4):377-382.

25. Naylor FD. A state-trait curiosity inventory. Aust Psychol. 1981;16(2):172-183.

26. Tourangeau R, Yan T. Sensitive questions in surveys. Psychol Bull. 2007;133(5):859-883. 